\title{
Obesity Knowledge among Final-Year Medical Students in Norway
}

\author{
Catia Martins ${ }^{a, b} \quad$ Anette Norsett-Carr ${ }^{a}$ \\ ${ }^{a}$ Obesity Research Group, Department of Clinical and Molecular Medicine, Faculty of \\ Medicine, Norwegian University of Science and Technology (NTNU), Trondheim, Norway; \\ ${ }^{b}$ Centre for Obesity Research (ObeCe), Clinic of Surgery, St. Olav University Hospital, \\ Trondheim, Norway
}

\author{
Keywords \\ Obesity $\cdot$ Knowledge $\cdot$ Medical education $\cdot$ Management $\cdot$ Doctors
}

\begin{abstract}
Objectives: To assess the level of obesity knowledge in final-year medical students in Norway and to compare it to an expert group and first-year medical students. Methods: A 20-item questionnaire was specifically designed for this purpose (18 knowledge-based questions and 2 subjective questions looking at attitudes and self-perceived proficiency). All medical schools in Norway were included $(n=226)$. For comparison purposes, an expert group $(n=13)$ and first-year medical students $(n=96)$ were included. Results: Experts (81\%; 15 out of 18 (13.5$16.0)$ ) scored significantly higher than both final-year (60\%; 11 out of $18(9.0-12.0)$ ) and firstyear (48\%; 9 out of 18 (7.0-10.0)) students. Final-year students scored significantly higher than first-year students, but showed inadequate obesity knowledge, especially with regard to etiology, diagnosis, and treatment aspects. Subjective questions revealed that medical students trust their acquired knowledge, but feel pressured by time constraints and the complexity of lifestyle issues and experience barriers to long-term follow-up. Conclusion: Final-year medical students in Norway show an inadequate knowledge level within the obesity field, although a significant improvement is seen during the course of medical education. They also show a high self-perceived proficiency in dealing with obesity, despite several constraints/barriers.
\end{abstract}

\section{Introduction}

Obesity has become a challenge in medical care worldwide. One of the main professions in primary care dealing with obesity is the general practitioner (GP), and previous surveys have shown that the general public considers GPs to be a credible source of information on 
nutrition [1-4] and lifestyle advice [5]. Unfortunately only a small fraction of GPs discuss weight loss interventions [6], physical activity (PA) [4, 6, 7], and nutrition [6] with patients with obesity. To add to this, less than half of patients with obesity who seek advice for lifestyle-related problems are actually advised by their GP to lose weight [8]. Further data shows that medical professionals under-recognize obesity as a physical condition in adults as well as in children $[9,10]$. Moreover, a study of British GPs found that $73 \%$ of the physicians felt they should not be involved in weight management of obese children and families [11].

Several studies confirm the lack of self-proficiency amongst medical students, interns, and physicians $[12,13]$. GPs report several barriers to implementing public health advice to obese patients [4,5], including time constrains and lack of training from medical school. A recent US national analysis of physicians' perspectives on causes of obesity confirms this, stating that only one-third of patients with excess body mass received an obesity diagnosis and weight-related counselling [14]. Overall, GPs seem to recognize the need for adequate knowledge on causes and consequences of obesity, lifestyle issues, and treatment alternatives [14-17], but there is a suboptimal education and knowledge on weight management, especially in the long term. Medical students and GPs seem to understand the medical consequences of obesity, but diagnosis, treatment, and attitudes towards treating patients with obesity are areas often governed by inconsistencies, poor grasp of knowledge, and low efficacy $[6,10,18]$.

From our knowledge, no study has looked at the current practices and/or knowledge within obesity of Norwegian doctors or medical students, and how well prepared they perceive themselves to be in dealing with obesity beyond the medical treatment of comorbidities.

The primary aim of this study was, therefore, to assess the level of obesity knowledge in final-year medical students in Norway by comparison with an expert group and first-year medical students. The secondary aim was to evaluate the attitudes of final-year medical students to the treatment of patients with obesity and self-perceived proficiency in dealing with obesity.

\section{Material and Methods}

Study Design

This was a cross-sectional observational study where knowledge and perceptions on obesity were assessed and compared between experts, final-year and first-year medical students.

Subjects

All final-year medical students at all Norwegian medical faculties were asked to participate. Participation was voluntary and anonymous.

The expert group consisted of health care professionals who all work clinically with obesity and who were present at a regional obesity conference. The first-year medical students were asked to participate during their first week at medical school.

\section{Survey Procedure}

A 20-item self-completed questionnaire aimed at evaluating obesity knowledge was developed, including 18 closed questions and 2 subjective questions aimed at investigating possible attitudes of young doctors towards patients with obesity and their confidence in treating this patient group. Only final-year students were asked to complete subjective questions 19 and 20.

\section{Development and Validation}

As no appropriate validated questionnaire was found, one was specifically designed to suit the purpose of this study. Some items were taken from existing relevant questionnaires or similar surveys performed on medical personnel/students in order to create an item pool. Others were developed after extensive literature 
Martinsa,b and Norsett-Carra: Obesity Knowledge among Final-Year Medical Students in Norway

Table 1. Questionnaire - please choose only one answer for each one of questions below

\section{Physiology}

1. Which of the following alternatives best characterizes people with obesity (BMI $\left.\geq 30 \mathrm{~kg} / \mathrm{m}^{2}\right)$, compared to normal-weight individuals?

A. A lower resting metabolic rate (RMR)

B. Lower total energy expenditure (TEE) during physical activity given similar intensity and duration

C. A higher TEE

D. A decrease in carbohydrate metabolism

2. Which of the following alternatives is correct in terms of TEE and RMR?

A. Degree of fat-free mass (FFM) is crucial for RMR

B. RMR is not affected by gender, age or BMI $\left(\mathrm{kg} / \mathrm{m}^{2}\right)$

C. RMR accounts for approximately $50 \%$ of TEE in inactive individuals with obesity

D. Exercise-induced energy expenditure accounts for approximately $50 \%$ of TEE in an inactive individual with obesity

Etiology

3. Which of the following alternatives is considered to be the main reasons for an increase in overweight and obesity?

A. Lack of self-control

B. Genetics

C. Genetic predisposition in addition to inactivity and overabundance of food

D. Increasing use of medications that can lead to weight gain

E. Endocrine causes

4. Weight gain (WG) after a period of weight loss (WL), is one of the most profound challenges in obesity management. Which of the following alternatives represents the most likely contributor?

A. Reduction in motivation and lack of compliance

B. Reduction in RMR and a decrease in energy expenditure related to PA

C. Increase in hunger sensation and a decrease in satiety due to physiological adaptations to appetite control systems

D. Combination of $A+B+C$

\section{Diagnosis}

5. Which diagnostic criterion regarding obesity represents the current standard?

A. BMI $\left(\mathrm{kg} / \mathrm{m}^{2}\right)$

B. Presence of comorbidities

C. Body composition (fat-free mass vs. fat mass)

D. Amount of visceral adipose tissue (VAT)

6. When diagnosing obesity in children, which of the following tools is considered to be the best one to use?
A. BMI curve
B. Waist-to-hip ratio
C. Iso-BMI curve
D. Percentiles

7. Which of the patients would you most likely prioritize in terms of treatment for obesity?

A. Female 38 years old, BMI $50 \mathrm{~kg} / \mathrm{m}^{2}$, mild hypertension, knee and lower back pain

B. Male 34 years old, BMI $35 \mathrm{~kg} / \mathrm{m}^{2}$, diabetes type II, obstructive sleep apnea (OSAS)

C. Female 48 years old, BMI $32 \mathrm{~kg} / \mathrm{m}^{2}$, physically active, minor joint discomforts

D. Male 36 years old, BMI $45 \mathrm{~kg} / \mathrm{m}^{2}$, impaired fasting glucose, mild depression

searches and under the guidance of a clinical nutritionist and a consultant endocrinologist. A pilot questionnaire was assessed and validated by testing on an independent expert panel consisting of six specialist physicians, endocrinologists and surgeons, all affiliated with the Obesity Outpatient Clinic at St Olavs Hospital, Trondheim, Norway. Each question was scrutinized for its relevance to the project and difficulty level and modified accordingly if necessary.

The questionnaire was divided into eight different subcategories, in total 20 questions; physiology (2), etiology (2), diagnosis (3), measure for treatment outcome (1), conservative treatment of obesity (4), surgical treatment of obesity (2), consequences of obesity (1), and long-term maintenance of body weight (3) as well 
Martinsa,b and Norsett-Carra: Obesity Knowledge among Final-Year Medical Students in Norway

Table 1. Continued

Goals for Obesity Treatment

8. Which alternative in terms of reduction in body weight is considered to give significant improvements in health?

A. $10-15 \mathrm{~kg} \mathrm{WL}$

B. $5-10 \%$ WL from baseline weight

C. A reduction in BMI category (e.g. from WHO class III to WHO class II)

D. A reduction in waist circumference $(\mathrm{cm})$ by $10 \%$

Conservative Treatment of Obesity

9. What is considered to be the most optimal form for exercise in treating obesity?

A. $4 \times 4$ high-intensity interval training (HIIT)

B. Combined endurance and resistance exercise

C. Resistance exercise

D. Exercising in the moderate intensity zone/fat burning zone

10. What is considered to be the most optimal strategy for lifestyle treatment of obesity?
A. Changing dietary habits
B. Combination of diet and exercise
C. Increasing physical activity levels (PALs)
D. Cognitive behavioral therapy (CBT)
E. Combination of diet, exercise and CBT

11. When considering long-term weight reduction, which diet is believed to be the most effective one?

A. Low carbohydrate - high fat (LCHF)

B. Low fat

C. Mediterranean diet

D. Any diet can give the same weight reduction given equal negative energy balance and long term compliance 12. Which of the following alternatives is considered to be the most appropriate recommendation when looking at conservative treatment of obesity?

A. A negative energy deficit of approximately $600 \mathrm{kcal} /$ day

B. $<20 \%$ of the energy in the diet comes from fat as a macronutrient

C. A weight loss of $>1.0 \mathrm{~kg} /$ week

D. A diet very low in energy $(<800 \mathrm{kcal} /$ day $)$

Surgery (Non-Conservative Treatment of Obesity)

13. Which of the following alternatives is the most correct one when looking at long-term outcomes of surgical treatment of obesity (gastric bypass, GBP)?

A. GBP improves the metabolic risk profile, but not primarily cardiovascular risk

B. Approximately $15 \%$ of patients experience suboptimal weight loss or significant weight regain

C. GBP does not produce a more significant WL after two years when compared to lifestyle treatment of obesity

D. Approximately $95 \%$ of patients who undergo GBP respond well when looking at WL

14. Which of the following alternatives represents the most common complication experienced after GBP?
A. Hypertension
B. Dyslipidemia
C. Low levels of vitamin B12, vitamin D, calcium, and iron
D. Osteoporosis

Consequences of Obesity

15. Which of the following alternatives are least associated with obesity?
A. DM2
B. Osteoporosis
C. Male infertility
D. Non-alcoholic fatty liver disease (NAFLD) 
Martinsa,b and Norsett-Carra: Obesity Knowledge among Final-Year Medical Students in Norway

Table 1. Continued

Weight Loss Maintenance - Long-Term Perspective

16. Which level of physical activity is recommended for individuals with obesity in order to maintain weight loss?

A. $30 \mathrm{~min}$ /day moderate intensity

B. Short 10 min bouts with high intensity 3 times/week

C. 45-60 min/day moderate intensity

D. 30 min HIIT 3 times/week

17. On average, which percentage do individuals who have lost weight through lifestyle changes are able to maintain a clinically significant WL for at least 1 year?
A. $20 \%$
B. $<10 \%$
C. $30 \%$
D. $>40 \%$

18. Which of the following alternatives is most associated with long-term WL maintenance?

A. A diet high in carbohydrates ( $\geq 55 \%$ of total energy intake)

B. Exercising at high intensity $>3$ times/week

C. Eating breakfast $>5$ days/week

D. Self-weighing $\geq 1$ times/month

Subjective Questions

19. Choose the alternative you agree the most with regarding possible reasons for you as a doctor feeling resistant to initialize treatment of obesity

A. There is not much I can accomplish during a 10-min consultation

B. Obesity is a very complex condition, so I prefer to focus on treating the comorbidities

C. There are few economic incentives in promoting public health/obesity prevention, and it is difficult charging fees for suggesting simple changes in diet and exercise routines

D. It is my duty to discuss weight issues with the patient, but long term follow-up and frequent consultations are beyond my capacity in busy surgery

E. I believe that most patients with obesity live in denial, and few methods are effective in maintaining weight, so I give them general advice and move on

20. Choose the alternative you agree the most with regarding your role as a medical professional who treats patients with obesity

A. I trust my acquired knowledge from university education and I know how to treat this patient

B. I prefer to refer the patient to tertiary care/specialist health care services because I suggest that obesity is a selfinflicted condition and it is beyond my reach to treat

C. I can handle treating the medical aspects of comorbidities, but not the complexity of the lifestyle issues

D. I fear that I may create poor doctor-patient dynamics by bringing up weight and lifestyle issues. The subject of body weight is such a sensitive topic, and discussing it may make the patient reluctant to keep me as their GP

as subjective questions (2). Each of the first 18 questions only had one correct answer, each answer weighted equally. The final two questions concerned the students' subjective attitude towards treating patients with obesity and their confidence in treating this patient group based on their perceived knowledge. Only the last two questions were exempt from weighting as there was no correct or incorrect answer (see questionnaire in table 1).

\section{Data Collection}

The four medical faculties in Norway (Trondheim, Oslo, Bergen, and Troms $\emptyset$ ) were approached via study coordinators as to obtain formal permission. In addition, student representatives for the respective final-year classes were emailed prior to testing and informed about the nature of the project.

Statistical Analysis

Statistical analysis was performed using IBM SPSS Inc. Statistics version 20 (Armonk, NY, USA). The significance level was set at $\mathrm{p}<0.05$ throughout the analysis. Age distribution is presented as mean values 
Table 2. Percentage of participants within each cluster group who selected the different options in Q1-Q4 of the questionnaire
Martinsa,b and Norsett-Carra: Obesity Knowledge among Final-Year Medical Students in Norway

\begin{tabular}{|c|c|c|c|}
\hline & Expert group & Final year & First year \\
\hline \multicolumn{4}{|c|}{ Physiology } \\
\hline \multicolumn{4}{|c|}{$\mathrm{Q} 1, \%$} \\
\hline $\mathrm{A}$ & $15.4^{\mathrm{a}}$ & $44.7^{b}$ & $53.1^{\mathrm{b}}$ \\
\hline B & 0 & 4.4 & 6.2 \\
\hline$C$ & $76.9^{a}$ & $36.9^{b}$ & $26.0^{b}$ \\
\hline $\mathrm{D}$ & 7.7 & 14.2 & 14.6 \\
\hline \multicolumn{4}{|c|}{$\mathrm{Q} 2, \%$} \\
\hline$A$ & $76.9^{a}$ & $73.9^{a}$ & $59.4^{b}$ \\
\hline B & 0 & 2.7 & 5.2 \\
\hline $\mathrm{C}$ & 23.1 & 15.5 & 25.0 \\
\hline $\mathrm{D}$ & 0 & 8.0 & 10.4 \\
\hline \multicolumn{4}{|c|}{ Etiology } \\
\hline \multicolumn{4}{|c|}{$\mathrm{Q} 3, \%$} \\
\hline A & $15.4^{\mathrm{a}}$ & $2.2^{\mathrm{b}}$ & $1.0^{\mathrm{b}}$ \\
\hline B & 0 & 0 & 0 \\
\hline$C$ & 84.6 & 94.6 & 96.9 \\
\hline $\mathrm{D}$ & 0 & 0 & 0 \\
\hline $\mathrm{E}$ & 0 & 0.4 & 0 \\
\hline \multicolumn{4}{|l|}{$\mathrm{Q} 4, \%$} \\
\hline $\mathrm{A}$ & 7.7 & 16.4 & 12.5 \\
\hline B & 7.7 & 5.3 & 8.3 \\
\hline $\mathrm{C}$ & 7.7 & 15.5 & 13.5 \\
\hline$D$ & 76.9 & 62.4 & 65.6 \\
\hline
\end{tabular}

Highlighted options and percentages denote the correct alternative. Presence of different superscript letters denote significant differences between groups $(\mathrm{p}<0.05)$.

and standard deviations $( \pm$ SD). To detect if there were significant differences between cluster groups in age, one-way ANOVA was used. Gender differences among groups were analyzed using chi-square test. As total score of the questionnaire was not normally distributed, non-parametric tests (Kruskal-Wallis) were used to look at differences among groups. Data is presented as median and interquartile range (IQR). Post-hoc Bonferroni correction was used to adjust for the possible presence of type I errors, as multiple comparisons were performed across participant groups. Chi-square was used when analyzing each individual question in order to investigate whether there were significant differences in terms of percentages of participants within each group who selected each option (correct or incorrect).

\section{Results}

\section{Demographic Profile of the Participants}

The final-year group was composed of 226 students, the first-year group of 96 students, and the expert group of 13 individuals. The distribution of gender was similar across all groups (70\% female). The mean age of all participants was $25.7 \pm 5.7$ years. As expected, there was a significant difference in age among groups $(\mathrm{p}<0.05)$, with experts being significantly older (46.2 \pm 10.7 years) than final-year and first-year students $(26.6 \pm 2.4$ and $20.7 \pm 1.9$ years, respectively) $(p<0.05)$ and final-year students being older than first-year students $(\mathrm{p}<0.05)$. 
Table 3. Percentage of people within each cluster group who selected the different options in Q5-Q8 of the questionnaire
Martinsa,b and Norsett-Carra: Obesity Knowledge among Final-Year Medical Students in Norway

\begin{tabular}{|c|c|c|c|}
\hline & Expert group & Final year & First year \\
\hline \multicolumn{4}{|c|}{ Diagnosis } \\
\hline \multicolumn{4}{|c|}{ Q5 (\%) } \\
\hline$A$ & $100.0^{a}$ & $95.1^{a}$ & $64.6^{b}$ \\
\hline $\mathrm{B}$ & 0 & 0 & 3.1 \\
\hline $\mathrm{C}$ & $0^{a}$ & $2.2^{\mathrm{a}}$ & $26.0^{\mathrm{b}}$ \\
\hline $\mathrm{D}$ & 0 & 2.2 & 6.2 \\
\hline \multicolumn{4}{|c|}{ Q6 (\%) } \\
\hline $\mathrm{A}$ & $0^{a}$ & $12.4^{\mathrm{a}}$ & $21.9^{\mathrm{b}}$ \\
\hline $\mathrm{B}$ & 0 & 5.3 & 35.4 \\
\hline$C$ & $92.3^{a}$ & $16.4^{b}$ & $32.3^{c}$ \\
\hline $\mathrm{D}$ & $7.7^{\mathrm{a}}$ & $65.9^{b}$ & $10.4^{\mathrm{b}}$ \\
\hline \multicolumn{4}{|c|}{ Q7, \% } \\
\hline A & 30.8 & 26.1 & 31.2 \\
\hline$B$ & $69.2^{a}$ & $58.4^{a}$ & $43.8^{b}$ \\
\hline $\mathrm{C}$ & 0 & 0.9 & 1.0 \\
\hline $\mathrm{D}$ & $0^{\mathrm{a}}$ & $14.2^{\mathrm{b}}$ & $24.0^{c}$ \\
\hline \multicolumn{4}{|c|}{ Treatment of obesity } \\
\hline \multicolumn{4}{|c|}{ Q8 (\%) } \\
\hline $\mathrm{A}$ & 0.0 & 0.0 & 1.0 \\
\hline$B$ & $100.0^{a}$ & $65.5^{b}$ & $35.4^{c}$ \\
\hline $\mathrm{C}$ & $0.0^{\mathrm{a}}$ & $15.9^{\mathrm{a}}$ & $45.8^{\mathrm{b}}$ \\
\hline $\mathrm{D}$ & 0.0 & 17.3 & 17.7 \\
\hline
\end{tabular}

Highlighted options and percentages denote the correct alternative. Presence of different superscript letters denote significant differences between groups $(\mathrm{p}<0.05)$

\section{Total Score of the Questionnaire}

The final-year students answered correctly 10.8 (9-12) out of 18 questions; a 60.0\% overall score, which was significantly higher $(\mathrm{p}<0.05)$ than that of first-year students $(9$ $(7-10), 47.8 \%)$, but significantly lower $(\mathrm{p}<0.05)$ than that of the expert group who scored correctly on average $14.6(13.5-16)$ questions (81.1\%). After 6 years of medical education, the average final-year student answered correctly on two additional questions $(12.2 \%$ difference) compared to first-year students.

\section{Objective Questions (Q1-Q18)}

Average scores on the objective questions of the questionnaire in all groups can be seen in tables 2-6.

Regarding Q1 on what characterizes people with obesity, 76.9\% of the experts chose the correct option C ('A higher total energy expenditure'), whilst the majority of both final-year and first-year students chose option A ('A lower resting metabolic rate'). A significantly larger percentage of experts selected the correct option, compared to both final-year (36.9\%) and first-year students $(26.0 \%)(\mathrm{p}<0.05)$, with no significant differences between the two student groups (table 2).

For Q2 on total energy expenditure and resting metabolic rate, there were no significant differences in the percentage of experts (76.9\%) and final-year students $(73.9 \%)$ who choose the correct option A ('Resting metabolic rate is mainly influenced by fat-free mass'). The percentage of first-year students choosing option A (59.4\%) was significantly lower ( $p<0.05)$ compared to the other two groups (table 2). 
Table 4. Percentage of participants within each cluster group who selected the different options in Q9-Q12 of the questionnaire
Martinsa,b and Norsett-Carra: Obesity Knowledge among Final-Year Medical Students in Norway

\begin{tabular}{clll}
\hline & Expert group & Final year & First year \\
\hline $\begin{array}{lll}\text { Conservative treatment of obesity } \\
\text { Q9, \% }\end{array}$ & & \\
A & 7.7 & 11.9 & 5.2 \\
$B$ & 76.9 & 65.9 & 65.6 \\
C & 0.0 & 7.8 & 1.0 \\
D & 15.4 & 9.4 & 28.1 \\
Q10, $\%$ & & & \\
A & 7.7 & 1.3 & 0.0 \\
B & 0.0 & 15.9 & 25.0 \\
C & 0.0 & 0.4 & 0.0 \\
D & 0.0 & 0.4 & 0.0 \\
E & $92.3^{a}$ & $81.9^{b}$ & $74.0^{b}$ \\
Q11, \% & & & \\
A & 0.0 & 5.3 & 17.7 \\
B & 0.0 & 7.5 & 28.1 \\
C & 7.7 & 19.9 & 11.5 \\
D & $92.3^{a}$ & $62.3^{b}$ & $42.7^{c}$ \\
Q12, \% & & & \\
A & $92.3^{a}$ & $68.6^{b}$ & $61.5^{b}$ \\
B & 0.0 & 15.9 & 14.6 \\
C & 7.7 & 9.3 & 17.7 \\
D & 0.0 & 5.8 & 6.2 \\
\hline
\end{tabular}

Highlighted options and percentages denote the correct alternative. Presence of different superscript letters denote significant differences between groups $(\mathrm{p}<0.05)$.

For Q3 on the etiology of obesity, a large percentage of people within all cluster groups answered correctly (option C: 'Genetic predisposition in addition to physical inactivity and excess energy intake'), with no significant differences between them (table 2).

For Q4, on weight regain, the majority in all groups choose the correct option D, with no significant difference between the groups. The most frequently chosen incorrect options in both final-year and first-year students was A: 'Weight regain caused by lack of compliance and motivation' and C: 'Weight regain caused by increased hunger and feeling less full due to adaptations in the appetite control system' (table 2).

Regarding Q5 on diagnostic criterions for obesity in adults, the majority in all groups scored correctly (option A: 'BMI'). However, a significantly larger $(p<0.05)$ percentage of experts and final-year students choose the correct answer, compared with first-year students. When looking at incorrect answers, option C ('Body composition') was wrongly chosen by a significantly larger $(\mathrm{p}<0.05)$ percentage of first-year students, compared to both other groups (table 3).

Regarding Q6 on diagnostic tools for overweight and obese children, the correct option was 'Iso-BMI charts' (option C). Only $16.4 \%$ of final-year students answered correctly. A significantly larger $(p<0.05)$ percentage of first-year students chose the right option $(32.2 \%)$. Close to all of the participants within the expert group chose the correct option $(92.3 \%)$, which was significantly more frequent $(\mathrm{p}<0.05)$ than in the two students groups. The majority of final-year students (65.9\%) chose option D: 'Using percentiles to diagnose childhood obesity', which was significantly more frequent $(\mathrm{p}<0.05)$ than in both the expert group and the first-year students (table 3).

Regarding Q7 'Which obese patient to prioritize for treatment', a significantly lower $(\mathrm{p}<$ 0.05) percentage of first-year students scored correctly (option B: 'Male 34 years old, BMI 35 
Table 5. Percentage of participants within each cluster group who selected the different options in Q13 and Q14 of the questionnaire
Table 6. Percentage of participants within each cluster group who selected the different options in Q16-Q18 of the questionnaire
Martinsa,b and Norsett-Carra: Obesity Knowledge among Final-Year Medical Students in Norway

\begin{tabular}{clll}
\hline & Expert group & Final year & First year \\
\hline $\begin{array}{lll}\text { Bariatric surgery } \\
\text { Q13, \% }\end{array}$ & & \\
A & 7.7 & 7.1 & \\
B & $61.5^{a}$ & $21.7^{b}$ & 15.6 \\
C & 0.0 & 24.8 & $17.7^{b}$ \\
D & 30.8 & 46.5 & 29.2 \\
Q14, \% & & & 37.5 \\
A & $0.0^{\mathrm{a}}$ & $0.0^{\mathrm{a}}$ & \\
B & $0.0^{\mathrm{a}}$ & $1.8^{\mathrm{a}}$ & $21.9^{\mathrm{b}}$ \\
C & $100.0^{a}$ & $98.7^{a}$ & $20.8^{\mathrm{b}}$ \\
D & 0.0 & 0.0 & $42.7^{b}$ \\
& & & 14.6 \\
\hline
\end{tabular}

Highlighted options and percentages denote the correct alternative. Presence of different superscript letters denote significant differences between groups $(\mathrm{p}<0.05)$.

\begin{tabular}{|c|c|c|c|}
\hline & Expert group & Final year & First year \\
\hline \multicolumn{4}{|c|}{$\begin{array}{l}\text { Consequences of obesity } \\
\text { Q15, \% }\end{array}$} \\
\hline $\begin{array}{r}\text { Q15, } \\
\text { A }\end{array}$ & $0.0^{a}$ & $27^{a}$ & $26.0^{b}$ \\
\hline$B$ & $84.6^{a}$ & $69.0^{b}$ & $38.5^{c}$ \\
\hline $\mathrm{C}$ & 15.4 & 18.1 & 24.0 \\
\hline $\mathrm{D}$ & 0.0 & 10.2 & 11.5 \\
\hline \multicolumn{4}{|c|}{ Weight loss maintenance } \\
\hline \multicolumn{4}{|c|}{ Q16, \% } \\
\hline A & $23.1^{\mathrm{a}}$ & $58.0^{\mathrm{b}}$ & $50.0^{\mathrm{b}}$ \\
\hline B & 0.0 & 1.8 & 0.0 \\
\hline C & $69.2^{a}$ & $29.2^{b}$ & $39.6^{b}$ \\
\hline D & 7.7 & 10.2 & 10.4 \\
\hline \multicolumn{4}{|c|}{$\mathrm{Q} 17, \%$} \\
\hline$A$ & $69.2^{a}$ & $49.2^{b}$ & $33.3^{c}$ \\
\hline B & 7.7 & 17.7 & 26.0 \\
\hline $\mathrm{C}$ & 23.1 & 32.2 & 31.2 \\
\hline $\mathrm{D}$ & 0.0 & 7.1 & 9.4 \\
\hline \multicolumn{4}{|c|}{ Q18, \% } \\
\hline A & 0.0 & 1.3 & 7.3 \\
\hline B & 15.4 & 54.9 & 52.1 \\
\hline C & $53.8^{a}$ & $36.7^{b}$ & $34.4^{b}$ \\
\hline D & $30.8^{a}$ & $7.1^{\mathrm{b}}$ & $6.2^{\mathrm{b}}$ \\
\hline
\end{tabular}

Highlighted options and percentages denote the correct alternative. Presence of different superscript letters denote significant differences between groups $(\mathrm{p}<0.05)$.

$\mathrm{kg} / \mathrm{m}^{2}$, diabetes type II, obstructive sleep apnea') (43.8\%), compared with both experts and final years $(69.2 \%$ and $58.4 \%$, respectively). Approximately $30 \%$ of the participants in all groups chose the incorrect option A (table 3).

For Q8, the right answer was B (' $5-10 \%$ WL from baseline weight'). Both groups of medical students scored significantly lower $(\mathrm{p}<0.05)(65.5 \%$ and $35.4 \%$ for final-year and first-year students, respectively) than the experts $(100 \%)$. A significantly higher $(\mathrm{p}<0.05)$ 
percentage of medical students chose option C ('A reduction in BMI category') as the incorrect alternative, compared to the expert group (table 3).

Regarding the optimal form of exercise in treating obesity (Q9), no significant differences were found when comparing groups, and the majority answered correctly (option B: 'A combination of endurance and resistance exercise'). The most commonly chosen wrong option was option D.

For Q10 on strategies for lifestyle treatment of obesity, the majority of people within all groups chose the correct answer (option E: 'A combination of physical activity, diet and cognitive behavioral therapy (CBT)'). However, significantly more $(\mathrm{p}<0.05)$ experts scored correctly (92.3\%), compared to both student groups $(81.9 \%$ and $74 \%$ in final-year and firstyear students, respectively). The most commonly chosen wrong option by students was option B: 'Combination of diet and exercise'.

Regarding the dietary approach considered to be the most optimal for the treatment of obesity (Q11), option D: 'Given the same energy deficit and compliance, all diets yield similar results' was the correct option. The majority of participants in all cluster groups chose the correct option, but compared with the two student groups a significantly higher percentage of people within the expert group $(92.3 \%)$ gave the right answer $(\mathrm{p}<0.05)$. Moreover, a significantly larger percentage of final-year students $(62.3 \%)$ selected the correct option, when compared with the first-year students $(42.7 \%)(\mathrm{p}<0.05)$ (table 4$)$.

When asking for which alternative is the current recommendation for conservative treatment of obesity (Q12), the correct option was A: 'A daily negative energy deficit of approximately $600 \mathrm{kcal} /$ day' and that was chosen by the majority of participants in all groups. However, the expert group $(92.3 \%)$ scored significantly higher $(\mathrm{p}<0.05)$ than both student groups (68.6\% and $61.5 \%$ for final-year and first-year students, respectively), with no significant differences between them (table 4).

In terms of surgical treatment of obesity (Q13), 61.5\% of the experts chose the correct option B ('Approximately 15\% of the patients undergoing gastric bypass will experience suboptimal weight loss or significant weight gain after surgery'). A significantly lower percentage of students ( $21.7 \%$ and $17.7 \%$ of final-year and first-year students, respectively), compared to experts $(61.5 \%)$, chose the correct option $(p<0.05)$. The incorrect option most frequently chosen was D, with no significant differences between groups.

The most common medical complication following gastric bypass (Q14) is considered to be low levels of vitamin B12, calcium, and iron (option C). Everyone within the expert group chose the correct answer, whilst $98.7 \%$ of the final-year students did so, but only $42.7 \%$ of first-year students ( $\mathrm{p}<0.05)$. The incorrect options A ('Hypertension') and B ('Dyslipidemia') where chosen significantly more frequently $(p<0.05)$ by first-year students than by the two other groups (table 5).

Regarding medical consequences of obesity (Q15), 84.6\% in the expert group chose the correct option B ('Osteoporosis'), which was significantly more frequent than in both student groups (69\% and 38.5\% in final-year and first-year students, respectively; $\mathrm{p}<0.05$ ). Compared with the final-year students, the first-year students more frequently did not answer correctly $(\mathrm{p}<0.05)$, and options A ('DM2') and C ('Male infertility') were the most common incorrect answers selected by the first-year students (table 6).

Regarding the amount of physical activity needed to maintain weight loss in individuals with obesity (Q16), at least 45-60 min of physical activity is recommended (option C). 69.2\% of the experts chose the correct option, which was significantly more frequent $(p<0.05)$ than in both student groups (29.2\% and 39.6\% in final-year and first-year students, respectively), with no significant differences between both students groups. The majority of both final-year and first-year students believed that option A (' $30 \mathrm{~min} /$ day with moderate intensity physical activity') was the correct answer (table 6). 
Q17 concerning the percentage of individuals being able to maintain a clinically significant weight loss for at least 1 year, the correct option was A ('20\%). A significantly higher percentage of experts $(69 \%)(\mathrm{p}<0.05)$ selected the correct option compared to both student groups $(49.2 \%$ or $33.3 \%)$, and first-year students scored significantly lower than final-year students $(\mathrm{p}<0.05)$ (table 6).

Q18 on alternatives most likely associated with long-term weight loss maintenance, was answered correctly by $53.8 \%$ of the experts in that 'Eating breakfast is the element most strongly associated with success at maintaining long-term weight loss' (option C). There was no difference when comparing final-year and first-year students, but they both achieved significantly lower results $(\mathrm{p}<0.05)$ than the experts $(36.7 \%$ and $34.4 \%$ respectively). The majority of final-year and first-year students chose option B (table 6).

Regarding possible reasons for medical doctors to feel resistant to initialize treatment of obesity (Q19), the majority of final-year students (40.7\%) chose option D. Approximately $20 \%$ chose option $\mathrm{A}$ or $\mathrm{C}$.

For Q20, regarding the role of medical doctors in treating patients with obesity, option A was the most commonly chosen alternative across medical schools $(47.3 \%)$, followed by option C (28.3\%).

\section{Discussion}

In crude numbers, experts scored correctly on 4 more questions than final-year students (14.6 vs. 10.8), and 6 years of medical education produced a difference of 2 more correct answers (10.8 vs. 8.6). The most profound differences were found in categories relating to physiology, diagnosis, long-term treatment, and weight management. As expected, the expert group achieved a significantly higher total score compared to final-year and first-year students, but a surprisingly high percentage of experts answered incorrectly on questions regarding which patient to prioritize for treatment (Q7) and long-term treatment outcome of bariatric surgery (Q13). Moreover, the majority of final-year students perceived themselves as competent in treating patients with obesity (Q19 and 20), but lack the confidence, time, resources, and capacity to commit to long-term follow-up of this complex patient group.

Delving more deeply into specific questions, several results of interest become clear. The majority of final-year students answered that one of the main causes of obesity is a lower metabolic rate. This is a common misconception both among clinicians and the general public, as discussed in recent articles $[19,20]$. Attributing a lower resting metabolic rate as the main cause of obesity may put the essential requirement for increased body weight - positive energy balance over time - second in line.

Regarding relapse, recent articles have investigated the physiological and psychological basis behind weight regain [7,21-23], increasing our understanding of why maintaining a reduced body weight over time is the biggest challenge in obesity management. A large number of final-year students attributed weight relapse to lack of compliance and motivation, adding evidence to the fact that patients with obesity are many times stigmatized by the medical profession and labelled as lazy and uncompliant. It is also of importance that doctors recognize the impact that even a minor weight loss (of $5-10 \%$ of initial body weight) can result in reducing comorbidities and improving quality of life (Q8) [24-26]. Only two-thirds of the final-year students were acquainted with this.

Overall, only $16.4 \%$ of final-year students knew that using iso-BMI is the optimal tool for diagnosing obesity in children and adolescents (Q6), compared to $32.3 \%$ of the firstyear students. Why a greater percentage of the first-year students scored correctly compared to the final-year students is not fully understood, as they had not been subject to any 
relevant teaching. Prior to the work of the International Taskforce of Obesity (IOTF) in the late 1990s, there was no commonly accepted standard for the definition of childhood obesity $[27,28]$. Childhood obesity is often overlooked, and GPs may as such contribute to underestimating the severity of weight gain in children $[29,30]$. In previous studies, the use of percentiles (most frequently chosen option by final-year medical students in the present study) has been shown to underestimate the progression of weight gain and obesity in children [31, 32].

Another key finding was that the majority of participants in both student groups believe erroneously that $95 \%$ of bariatric surgery patients respond well after gastric bypass (Q13) $[33,34]$, suggesting that bariatric surgery is a cure for obesity.

Regarding the subjective questions (Q19 and Q20), the majority of final-year students acknowledge weight management and obesity treatment as being a part of their professional role (Q19), but long-term follow-up is difficult and beyond their perceived capacity. Paradoxically, the main finding in a recent analysis by Jones et al. [35] was that GPs play a crucial part in initiating interventions and supporting families affected by obesity. The second most chosen option (A: 'There is not much I can do during a 10-minute consultation') suggests a feeling of futility in trying to intervene. Time constraints implemented on GPs can challenge the most designated young doctor in a busy surgery. Coupled with gaps in knowledge, lack of understanding of treatment, and poor confidence in abilities may increase stigma previously known to arise from medical personnel dealing with obesity [36, 37]. For Q20, final-year students appear to realize that weight and lifestyle issues are part of the job (option A), and feel confident in treating medical complications. This trend in attitude is reinforced when considering that the second most chosen option was C: "The medical side of obesity is easier to handle for the doctor than the weight and lifestyle problems'. This has been investigated previously $[38,39]$, but never before in Norwegian medical students, confirming the need to evaluate the foundations of obesity treatment in primary care.

This study presents several strengths. Firstly, all medical schools in Norway were included. Secondly, all final-year students were tested within a 6-week period, minimizing the difference in knowledge levels, and first-year students were tested at their first day of medical school. Thirdly, none of the students was aware of the nature of the questions prior to being tested or had access to information during testing. Fourth, an expert group composed of professionals working with clinical obesity was enrolled to serve as a comparison. The development of a specifically designed questionnaire also adds to the strengths of this study. However, test-retest of the questionnaire was not performed, as that would most likely be biased considering the students quick access to information as well as yearning for further learning. Also, the expert group was rather small, in comparison to both student groups, and time constraints resulted in testing only first-year students at one location (Trondheim).

In conclusion, the results of this study show a significant improvement in obesity knowledge during the course of medical education in Norway, but suggest gaps in understanding, particularly with regard to etiology, diagnosis, and treatment. Moreover, analysis of subjective questions shows negative attitudes towards time-consuming follow-up, treatment outcomes, and confidence in weight management.

\section{Acknowledgments}

We would like to thank Prof. Bård Kulseng for help in the development and validation of the questionnaire. We would also like to thank the Medical Faculty at the Norwegian University of Science and Technology for funding this study. 
Martinsa,b and Norsett-Carra: Obesity Knowledge among Final-Year Medical Students in Norway

\section{Funding}

This study was funded by the Medical Faculty, Norwegian University of Science and Technology.

\section{Disclosure Statement}

The authors declare no conflicts of interest.

\section{References}

1 Visser F, Hiddink G, Koelen M, van Binsbergen J, Tobi H, van Woerkum C: Longitudinal changes in GPs' task perceptions, self-efficacy, barriers and practices of nutrition education and treatment of overweight. Fam Pract 2008;25(suppl 1):i105-i111.

2 Sacerdote C, Fiorini L, Rosato R, Audenino M, Valpreda M, Vineis P: Randomized controlled trial: effect of nutritional counselling in general practice. Int J Epidemiol 2006;35:409-415.

3 Hiddink G, Hautvast J, Van Woerkum C, Fieren C, Van't Hof M: Consumers' expectations about nutrition guidance: the importance of primary care physicians. Am J Clin Nutr 1997;65(suppl 2):1974S-1979S.

4 Lobelo F, Duperly J, Frank E: Physical activity habits of doctors and medical students influence their counselling practices. Br J Sports Med 2009;43:89-92.

5 Abramson S, Stein J, Schaufele M, Frates E, Rogan S: Personal exercise habits and counseling practices of primary care physicians: a national survey. Clin J Sport Med 2000;10:40-48.

6 Vetter ML, Herring SJ, Sood M, Shah NR, Kalet AL. What do resident physicians know about nutrition? An evaluation of attitudes, self-perceived proficiency and knowledge. J Am Coll Nutr 2008;27:287-298.

7 Sumithran P, Proietto J: The defence of body weight: a physiological basis for weight regain after weight loss Clin Sci 2013;124:231-241.

8 Foster GD, Wadden TA, Makris AP, Davidson D, Sanderson RS, Allison DB, Kessler A: Primary care physicians' attitudes about obesity and its treatment. Obes Res 2003;11:1168-1177.

9 Laws R: Current approaches to obesity management in UK primary care: the Counterweight Programme. J Hum Nutr Diet 2004;17:183-190.

10 Block JP, DeSalvo KB, Fisher WP: Are physicians equipped to address the obesity epidemic? Knowledge and attitudes of internal medicine residents. Prev Med 2003;36:669-675.

11 Gage H, Erdal E, Saigal P, Qiao Y, Williams P, Raats MM: Recognition and management of overweight and obese children: A questionnaire survey of general practitioners and parents in England. J Paediatr Child Health 2012; 48:146-152.

12 Adams KM, Lindell KC, Kohlmeier M, Zeisel SH: Status of nutrition education in medical schools. Am J Clin Nutr 2006;83:941S-944S

13 Temple NJ: Survey of nutrition knowledge of Canadian physicians. J Am Coll Nutr 1999;18:26-29.

14 Bleich SN, Bennett WL, Gudzune KA, Cooper LA: National survey of US primary care physicians' perspectives about causes of obesity and solutions to improve care. BMJ Open 2012;2: pii: e001871.

15 Gerner B, McCallum Z, Sheehan J, Harris C, Wake M: Are general practitioners equipped to detect child overweight/obesity? Survey and audit. J Paediatr Child Health 2006;42:206-211.

16 Dettori H, Elliott H, Horn J, Leong G: Barriers to the management of obesity in children - a cross sectional survey of GPs. Austr Fam Physician 2009;38:460-464.

17 Buffart LM, Allman-Farinelli M, King LA, van der Ploeg HP, Smith BJ, Kurko J, Bauman AE: Are general practitioners ready and willing to tackle obesity management? Obes Res Clin Pract 2008;2:189-194.

18 Fogelman Y, Vinker S, Lachter J, Biderman A, Itzhak B, Kitai E: Managing obesity: a survey of attitudes and practices among Israeli primary care physicians. Int J Obes Relat Metab Disord 2002;26:1393-1397.

19 Casazza K, Fontaine KR, Astrup A, Birch LL, Brown AW, Bohan Brown MM, Durant N, Dutton G, Foster EM, Heymsfield SB: Myths, presumptions, and facts about obesity. N Engl J Med 2013;368:446-454.

20 Demaria AN: The multiple challenges of obesity. J Am Coll Cardiol 2013;61:784-786.

21 Sumithran P, Prendergast LA, Delbridge E, Purcell K, Shulkes A, Kriketos A, Proietto J: Long-term persistence of hormonal adaptations to weight loss. N Engl J Med 2011;365:1597-1604.

22 King NA, Caudwell P, Hopkins M, Byrne NM, Colley R, Hills AP, Stubbs JR, Blundell JE: Metabolic and behavioral compensatory responses to exercise interventions: barriers to weight loss. Obesity (Silver Spring) 2007;15: 1373-1383.

23 Morton G, Cummings D, Baskin D, Barsh G, Schwartz M: Central nervous system control of food intake and body weight. Nature 2006;443:289-295.

24 Goodpaster BH, Kelley DE, Wing RR, Meier A, Thaete FL: Effects of weight loss on regional fat distribution and insulin sensitivity in obesity. Diabetes 1999;48:839-847.

25 Wing RR, Hill JO: Successful weight loss maintenance. Annu Rev Nutr 2001;21:323-341. 
Martinsa,b and Norsett-Carra: Obesity Knowledge among Final-Year Medical Students in Norway

26 Douketis J, Macie C, Thabane L, Williamson D: Systematic review of long-term weight loss studies in obese adults: clinical significance and applicability to clinical practice. Int J Obes 2005;29:1153-1167.

27 Dietz W, Robinson T: Use of the body mass index (BMI) as a measure of overweight in children and adolescents. J Pediatr 1998;132:191-193.

28 Cole TJ, Bellizzi MC, Flegal KM, Dietz WH: Establishing a standard definition for child overweight and obesity worldwide: international survey. BMJ 2000;320:1240.

29 Walker O, Strong M, Atchinson R, Saunders J, Abbott J: A qualitative study of primary care clinicians' views of treating childhood obesity. BMC Fam Pract 2007;8:50.

30 King LA, Loss JH, Wilkenfeld RL, Pagnini DL, Booth ML, Booth SL: Australian GPs' perceptions about child and adolescent overweight and obesity: the Weight of Opinion study. Br J Gen Pract 2007;57:124-129.

31 Nader PR, O’Brien M, Houts R, Bradley R, Belsky J, Crosnoe R, Friedman S, Mei Z, Susman EJ: Identifying risk for obesity in early childhood. Pediatrics 2006;118:e594-e601.

32 Speiser PW, Rudolf MC, Anhalt H, Camacho-Hubner C, Chiarelli F, Eliakim A, Freemark M, Gruters A, Hershkovitz E, Iughetti L: Childhood obesity. J Clin Endocrinol Metab 2005;90:1871-1887.

33 Thompson C, Slattery J, Bundga M, Lautz D: Peroral endoscopic reduction of dilated gastrojejunal anastomosis after Roux-en-Y gastric bypass: a possible new option for patients with weight regain. Surg Endosc 2006;20: 1744-1748.

34 Karmali S, Brar B, Shi X, Sharma AM, de Gara C, Birch DW: Weight recidivism post-bariatric surgery: a systematic review. Obes Surg 2013;23:1922-1933.

35 Jones KM, Dixon ME, Dixon JB: GPs, families and children's perceptions of childhood obesity. Obes Res Clin Pract 2014;8:e140-e148.

36 Puhl RM, Latner JD: Stigma, obesity, and the health of the nation's children. Psychol Bull 2007;133:557.

37 Puhl R, Brownell KD: Bias, discrimination, and obesity. Obes Res 2001;9:788-805.

38 Mercer S, Tessier S: A qualitative study of general practitioners' and practice nurses' attitudes to obesity management in primary care. Health Bull 2001;59:248-253.

39 Epstein L, Ogden J: A qualitative study of GPs' views of treating obesity. B J Gen Pract 2005;55:750-754. 